Research paper

\title{
Indirect interactions between crops and natural vegetation through flower visitors: the importance of temporal as well as spatial spillover
}

\author{
Lavhelesani D. Simba, ${ }^{\mathrm{a}, \mathrm{b}}$, Stefan H. Foord ${ }^{\mathrm{a}}$, Elisa Thébault ${ }^{\mathrm{c}}$, F.J.Frank van Veen ${ }^{\mathrm{d}}$, \\ Grant S. Joseph ${ }^{\mathrm{a}, \mathrm{e}}$, Colleen L. Seymour ${ }^{\mathrm{b}, \mathrm{e}, *}$ \\ ${ }^{a}$ Department of Zoology and South African Research Chair for Biodiversity Value and Change, University of Venda, Private Bag X5050, Thohoyandou, South Africa \\ ${ }^{\mathrm{b}}$ South African National Biodiversity Institute, Kirstenbosch Research Centre, Private Bag X7, Claremont, 7735, South Africa \\ c CNRS, Sorbonne Universités, UPMC Univ Paris 06, Institute of Ecology and Environmental Sciences of Paris, 4 Place Jussieu, 75005 Paris, France \\ ${ }^{\mathrm{d}}$ Centre for Ecology and Conservation, College of Life and Environmental Sciences, University of Exeter, Penryn Campus, TR10 9FE, Cornwall, UK \\ ${ }^{\mathrm{e}}$ FitzPatrick Institute of African Ornithology, DST/NRF Centre of Excellence, Department of Biological Sciences, University of Cape Town, Rondebosch, 7701, South Africa
}

\section{A R T I C L E I N F O}

\section{Keywords:}

Crop pollination

Ecosystem services

Facilitation

Indirect effects over time

Network analysis

Wild pollinators

\begin{abstract}
A B S T R A C T
As the Anthropocene advances, understanding the complex web of interactions between species has become a central theme in the maintenance of biodiversity, ecosystem functions, and agricultural systems. Plant-flower visitor networks yield insights into how natural vegetation supports crop pollination. Although crops themselves also support pollinators, the importance of spillover of flower-visiting pollinators from natural vegetation into croplands is increasingly appreciated. Natural vegetation not only provides forage and nesting sites, but can also support crop flower visitors when the crop is not flowering. We evaluated indirect effects between mango (the dominant tropical fruit crop globally) and wild plant species in neighbouring vegetation, and the factors determining these indirect effects, by constructing flower visitor networks. We constructed these networks for transects that included mango fields and neighbouring natural vegetation in north-eastern South Africa. Surveys were conducted before, during and after mango flowering, to allow evaluation of the importance of pollinator support when the crop was not in flower. Network analysis showed that potential indirect effects of other plant species on mango increased with flower abundance of those species, although this increase was less marked for species growing in natural vegetation. The cumulative (total, i.e. indirect effects summed) effect of natural vegetation on mango flower visitation was greater both during mango flowering and when it was not flowering. This is likely because of the greater plant diversity in natural systems, and because the combination of these species provided flowers over a protracted period. These positive indirect effects among plants flowering over extended periods of time have to date rarely been considered in crop pollination studies. Given the rapid expansion of high-intensity, high-yield monoculture plantings, such effects warrant further investigation.
\end{abstract}

\section{Introduction}

Ecological systems are composed of a host of interacting species and individuals. The interactions between these role-players influence not only the organisms involved, but ecosystem functioning, as they combine to form complex networks at a range of scales (Pocock et al., 2016). As the Anthropocene advances, indirect interactions (that is, the effects of one species on another, mediated by a third species) via pollination of terrestrial plants emerges as key to maintenance of biodiversity, ecosystem function, and agricultural production (Pocock et al., 2016; Sauve et al., 2016; Sotomayor and Lortie, 2015). This is because perturbations can have unforeseen consequences for a number of species via shared resources.

The study of mutualistic networks can provide insight in a number of applied areas, from restoration ecology, the effects of alien species and biological control to climate change, agro-ecology and habitat management (Memmott, 2009). A pollination network is a type of mutualistic network that links flowers and their visitors via their interactions. Pollination networks quantify the number and identity of flower-visitors to various plant species present in a community, allowing elucidation of which plant species interact with other plant species via their shared visitors. This can yield crucial insights. For example, rare plant species have been found to rely on more common species via shared pollinators (Gibson et al., 2006), illustrating the

\footnotetext{
* Corresponding authors at: South African National Biodiversity Institute, Kirstenbosch Research Centre, Private Bag X7, Claremont, 7735, South Africa

E-mail addresses: simba.lavhelesani@gmail.com (L.D. Simba), stefan.foord@univen.ac.za (S.H. Foord), elisa.thebault@upmc.fr (E. Thébault), f.j.fvan-veen@exeter.ac.uk (F.J.F. van Veen), karoogrant@gmail.com (G.S. Joseph), c.seymour@sanbi.org.za (C.L. Seymour).
} 
importance to the system of species previously considered to be mere weeds. Similarly, rare plant species may also share pollinators with alien invasive species (Carvalheiro et al., 2008), and such knowledge can allow management to mitigate for the removal of alien species from the system while ensuring continued pollination of rare species.

Over the last decade, the importance of facilitation of crop pollination via shared pollinators has risen to prominence, particularly through spatial spillover from natural or semi-natural vegetation (Klein et al., 2007). A review of 23 studies performed on 16 crops found marked and exponential declines in pollinator visitation rate to crops with distance to natural vegetation (Ricketts et al., 2008).

Crops themselves also support pollinators, and mass flowering crops and their associated weeds can see large increases in flower visitor densities (e.g., Westphal et al., 2003; Hagen and Kraemer 2010), which can spill over into natural vegetation. Croplands typically represent habitats impoverished in both structure and diversity (Ehlers Smith et al., 2015) however, and flower visitors often require natural vegetation for nesting sites and alternative forage resources (Williams and Kremen, 2007).

Interactions between plants via shared pollinators can be either facilitative or competitive. Plant species flowering concurrently may compete with each other for pollinator attention, or may inhibit pollination in other species via heterospecific pollen deposition. Alternatively, they may facilitate each other, by attracting pollinators to the vicinity and supplementing pollinator diets. Plant species that support the same pollinators as species that flower at different times can be considered to be purely facilitative, as they ensure pollinator survival by providing forage. Flower visitor species that are active for longer periods of the year than crop flowers are available require alternative resources before and/or after crop flowering to sustain populations, and the plant species that provide these resources can therefore be viewed as playing a facilitative role. Facilitative spillover effects can therefore occur not only in space, but also over time (Bjerknes et al., 2007), as native wild or exotic plant species may support crop pollinators when crops are not in flower (Nel et al., 2017). Crops may also play this role, as early flowering crops can also support pollination of late-flowering crops (Riedinger et al., 2014).

To date, most studies relating landuse to spillover effects have occurred in temperate, ecologically-transformed regions in the northern hemisphere (Henri et al., 2015; Sotomayor and Lortie, 2015). In addition, approximately half of the data used in thirteen recent meta-analyses on global pollination ecology were collected from only 5 developed countries, with the entire African continent contributing only $4 \%$ of the data (Archer et al., 2014). Agricultural and natural systems in the developed world are spatially-constrained, with little scope for change, in contrast to the rapid agricultural spatial shifts occurring in the tropics (McIntyre et al., 2009). The Food and Agricultural Organisation (FAO) has earmarked much of the Guinea savanna for cropland to meet both future nutritional needs both within and beyond Africa (Food and Agricultural Organisation of the United Nations, 2009), and sub-Saharan crop production will need to increase by $20 \%$ over the next decade (McIntyre et al., 2009). Against this background, we focussed our study on the dominant, and economically most important tropical fruit globally, mango Mangifera indica ([L., Anacardiaceae; Food and Agriculture Organisation, 2003).

We surveyed mango fields and the surrounding natural vegetation in north-eastern South Africa to investigate the patterns in, and extent of, indirect effects between natural vegetation and the crop, mediated by flower visitors in mango fields and natural vegetation. Previous studies have found that natural vegetation in the area is a source of both flower visitors (Carvalheiro et al., 2010, 2012; Geslin et al., 2016) and natural enemies of crop pests (Henri et al., 2015; Morgan et al., 2017) in mango fields. Mangos in turn have been shown to harbour pests that can spill over into natural vegetation (Moxley et al., 2017), and it is likely that pollinators, too, spill over into natural vegetation. How the presence of mango fields affects flower visitors within the natural vegetation, and whether natural vegetation is important to mango flower visitors when mango is not flowering (therefore facilitating mango flower visitation) remains unknown, however.

We use food-web (network) analyses to identify and quantify indirect effects between the mango crop and species in the natural vegetation. Specifically, we used Müller's index (Müller et al., 1999) to calculate the potential of each plant species to influence all other plant species via shared pollinators. This index quantifies how much one plant species contributes to the diets of the flower visitors of another plant species.

Various factors would be expected to influence the strength of these indirect effects. For example, plant species with high floral abundance can be particularly influential for other plant species through shared pollinators, because plants offering more resources should be visited more frequently (Carvalheiro et al., 2014). We would therefore expect flower abundance to influence the size of indirect effects. All else being equal, flower visitors should be more likely to visit flowers that are nearby to the flower they have just visited, as organisms tend to minimise energy expenditure as far as possible in their activities. Therefore, proximity would also be expected to influence the size of indirect effects. In addition, species that flower when little else is flowering may be particularly important for flower visitors, and therefore also exhibit marked facilitative indirect effects on other plant species.

Finally, the main taxonomic groups (e.g. beetles, flies, bees and ants) visiting flowers may also mediate indirect effects differently. For example, syrphid flies have been found to show a preference for yellow over white flowers, whereas some bee species showed the opposite (Campbell et al., 2010). Different taxa may respond in various ways to different flower scents (Junker et al., 2010), flower size and abundance (Stang et al., 2006), or flower phenology, height, and nectar tube depth (Junker et al., 2010). Others may have behavioural tendencies or other constraints restricting the distance moved between plants. These differences affect the number and frequency of interactions. This in turn would be expected to influence the presence and size of interactive effects between plant species, as mediated by the different groups of pollinators. We therefore hypothesised that patterns in indirect interactions should vary between the main flower visiting groups.

Therefore, in this study, we asked (i) what is the size of the potential indirect effects between mango and wild plant species, and (ii) what factors determine the size of these indirect effects in mango fields and in natural vegetation? We also used network visualisation to assess whether patterns of visitation to the crop and natural vegetation differ between the major taxonomic flower-visiting groups (i.e. Diptera, Hymenoptera and Coleoptera).

\section{Methods and materials}

\subsection{Study area and design}

This study was conducted on three farms (Bavaria, Mohlatsi and Venden) near Hoedspruit (Maruleng municipality) within the Kruger to Canyons Biosphere, Limpopo Province, South Africa (24 $24^{\prime} 58.44^{\prime \prime} \mathrm{S}$ and $30^{\circ} 52^{\prime} 35.13^{\prime \prime}$ E). Bavaria and Venden are situated along the R527 road, west of Hoedspruit, $6.8 \mathrm{~km}$ away from each other, while Mohlatsi is $21.4 \mathrm{~km}$ south-west and $14.8 \mathrm{~km}$ south of Bavaria and Venden, respectively. On each farm, rows of windbreak trees (Casuarina sp.) divide the blocks of mango trees $(\sim 70 \times 150 \mathrm{~m})$. Blocks contain a single cultivar, and we sampled blocks containing Kent, Tommy Atkins, Sensation and Suzie. At each farm, we established transects, at least $250 \mathrm{~m}$ apart, which ran perpendicular to the edge between the natural vegetation and mango fields. Transects were composed of 10 plots $(25 \mathrm{~m} \times 3 \mathrm{~m}$ ) that ran parallel to the edge between mango fields and the natural vegetation at distances of $200 \mathrm{~m}, 100 \mathrm{~m}, 50 \mathrm{~m}, 10 \mathrm{~m}$ and $1 \mathrm{~m}$ from the edge between the two habitats, into each habitat type (i.e, mango or natural vegetation). There were four such transects in Bavaria 
and three each in Mohlatsi and Venden (Supplementary information, Figure A1).

\subsection{Sampling}

We surveyed flower visitor-flower interactions in the plots in each transect once a month from June - October 2013, with an additional survey in January 2014 (yielding 6 months of surveys) between $08 \mathrm{~h} 00$ and $15 \mathrm{~h} 00$, to allow us to capture variability in flower visitor assemblages over space and time (Baldock et al., 2011; Stone et al., 1998). Surveys were conducted on warm, windless days. Mango begins flowering in July, with peak flowering in mid-August, ceasing by the end of September. December, January and February represent the core months of the wet season, so a number of plant species are flowering in the natural vegetation in January. In the dry season, when mango is flowering, flowers on plants in the natural vegetation are relatively rare. All flowering plants observed were identified, and the total number of flowers per species per plot recorded. As mango is a hyperabundant flowering species, the total number of flowers was estimated by counting the number of open flowers of three randomly-selected inflorescences (Carvalheiro et al., 2010). The average was multiplied by the total number of inflorescences counted in the plot. For species within the Asteraceae and Mimosoideae, inflorescences were counted instead of flowers. Flower visitors were observed for $10 \mathrm{~min}$ at each plot, recorded and collected; each time a flower visitor was encountered, the clock was stopped while observing interactions with plants within the plot, until the flower visitor left the plot and timing resumed. Observed flower visitors were collected and preserved in ethanol for identification to species level, where possible, or morphospecies. A pinned reference collection is housed in the insect collection at the University of Venda, Thohoyandou, South Africa.

\subsection{Indirect interactions between mango and other plant species}

We used the data collected over all six months to build a quantitative flower visitor network for each transect, producing a total of ten networks. To compare the potential for wild plant species to indirectly influence mango during mango flowering and when mango was not flowering, both in mango fields and in natural vegetation, each plant species was represented by several nodes in the networks if it flowered both when the crop was flowering and when it was not, and/or if it was present in both habitats. For example, in one transect, Commelina erecta was flowering in mango fields both when mango was flowering, and when it was not flowering. C. erecta was also found in natural vegetation when mango was not flowering. This species thus appeared as three nodes in the corresponding network.

We used the approach developed by Müller and collaborators (Müller et al., 1999) to calculate potential indirect interactions between mango and wild plant species in these 20 flower visitor networks. Müller's index is a measure between zero and one which, when applied to flower visitor networks, quantifies how much a given plant species (hereafter "acting plant") might contribute to the diets of the flower visitors visiting another plant species (hereafter "target plant", Carvalheiro et al., 2014). Müller's index for the effect of species $j$ on species $i$ is given by:

$d_{i j}=\sum_{k}\left(\frac{\alpha_{i k}}{\sum_{l} \alpha_{i l}} \times \frac{\alpha_{j k}}{\sum_{m} \alpha_{m k}}\right)$

where $d_{i j}$ summarises interactions between plant species $i$ and $j$ via all shared flower visitors. The fraction of flower visitors to plant species $i$ that belong to visitor species $k$, is given by $\frac{\alpha_{i k}}{\sum_{l} \alpha_{i l}}$, and the fraction of visitor species $k$ visiting flower species $j$ is given by: $\frac{\alpha_{j k}}{\sum_{m} \alpha_{m k}}$. By construction, zero thus indicates no shared flower visitors between the two plant species (no influence of one species on another) and a value close to one indicates that the diet of all the visitors of the target plant depends mostly on the acting plant. Potential indirect interactions between two plant species are highly asymmetrical if one plant species contributes far more to the diets of shared flower visitors than the other. It should be noted that $d_{i i}$, as defined in Eq. (1), represents the relative contribution of a given plant species $i$ to the overall diet of its own flower visitors (e.g. $d_{i i}=1$ for plants sharing no flower visitors with other plant species in a network). In addition, by definition, $\sum_{j} d_{i j}=1$, meaning that all the flower visitors visiting species $i$ fully depend on the plants present in the network for their diets.

We also assessed the total contribution of plants in the natural vegetation and those in mango fields to supporting mango flower visitors when mango was and was not flowering, using all the data aggregated from all study sites. The total of indirect effects of all plant species on mango by definition always adds up to one in a given network. We therefore summed the indirect effects (i.e. Müller's index) of plant species on mango, when mango was flowering and when mango was not flowering, for each habitat (i.e., natural vegetation and mango fields). All flower visitor networks were analysed using the bipartite package in R, with the function PAC used to calculate the Müller's index (Dormann et al., 2008).

\subsection{Statistical analysis}

We first compared the size of indirect effects on mango by other species with its effect on them using a paired $t$-test. To assess the average effect of other plants on mango and vice versa, and what determines the size of these indirect effects, we used Generalised linear mixed models (GLMM). We set the effect on mango (target plant) by other plant species (acting plants) as calculated using Müller's index, calculated from networks constructed per transect $(n=10)$, as the dependent variable. We set flower abundance, whether mango was flowering or not, and habitat (i.e., crop or natural vegetation) and the interaction between these as fixed explanatory variables, and farm as a random effect. We also repeated these models using the effect of mango on other plant species as the dependent variable for the same 10 transects.

We first assessed what determines the existence of an indirect effect between mango and other plant species using a binomial error structure, and then assessed what determines the strength of those indirect effects with mango on the remaining zero-truncated data using a gamma error structure with log link. We constructed models using various combinations of explanatory variables and interactions between them. We selected the best model using corrected Akaike Information Criteria (AICc), assuming that the best model was that with an AICc value 2 or more units lower than the AICc values for any other models. When the difference in AICc values between models was $<2$, we obtained parameter estimates using model averaging based on Akaike weights, using package MuMIn (Barton, 2016), in R. We calculated the variance explained by fixed and random effects (i.e., marginal and conditional $\mathrm{R}^{2}$ ) for the best models (Johnson, 2014; Nakagawa et al., 2017; Nakagawa and Schielzeth, 2013).

We also constructed general quantitative flower visitor webs based on the interactions per plant for all farms and aggregated over the full 6 months of the study for the four main groups of flower visitors (i.e., beetles, flies, bees and ants), to allow visualisation of how these groups mediated interactions between plant species.

\section{Results}

3.1. Size of potential effects between mango and plant species in cropland and natural vegetation

Mango shared $85 \%$ of its flower visitors with 38 plant species from 17 families (Fig. 1). Of these, 7 species were exotic weeds found in 
(a)

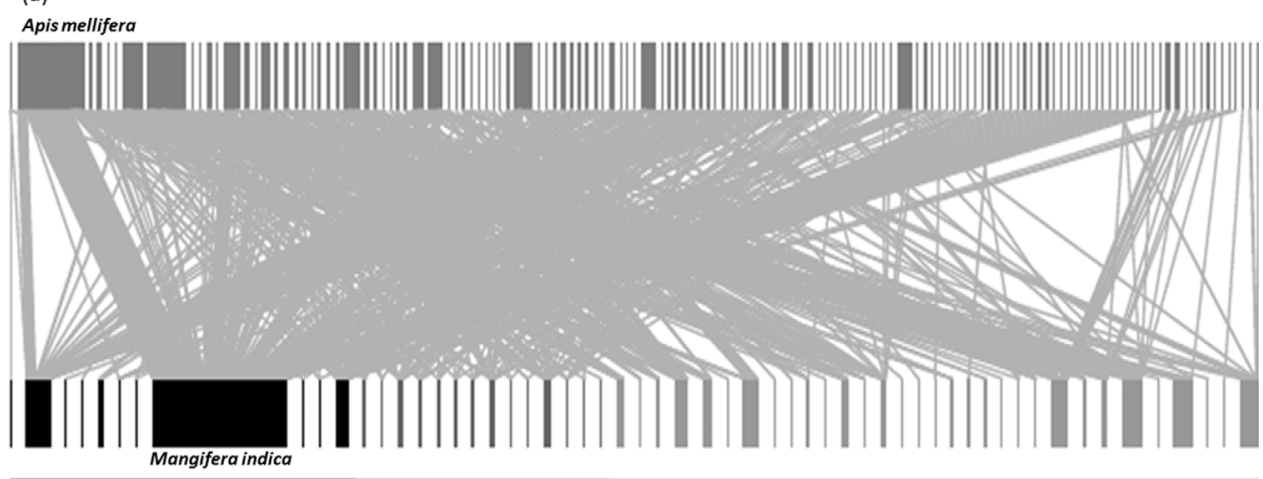

Plants in mango fields only Plants in mango fields \& natural vegetation
Plants in natural vegetation only

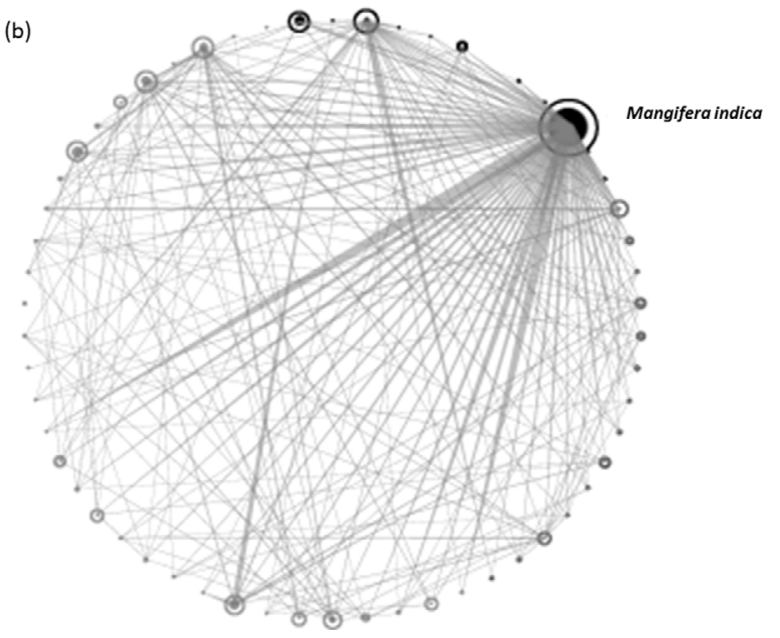

Fig. 1. Flower visitation web based on pooled data for all farms in mango fields and natural vegetation for all months sampled (June-October 2013 and January 2014). Plants constitute the bottom row of the web and flower visitors the top row. Plants found in mango fields are marked in black, those in both mango and natural vegetation in dark grey, and those in natural vegetation in light grey. The widths of rectangles represent overall species abundance in transects and the size of the lines connecting them represents the frequency of interactions observed (a). Species details are given in Fig. 4 and related Supplementary information (Tables S1 and S2). The quantitative overlap diagram (b) shows plants arranged in a circle, and are connected when they share flower visitors. The width of a link indicates the degree to which one species acts as a source of flower visitors for another. The size of the circle outline for each plant is an indication of the relative abundance of flower visitors visiting that plant species, and the amount of that circle that is shaded represents the proportion of times those flower visitors are seen on that particular plant species out of all that flower visitor species' visits to all plant species. mango fields, 20 species were in natural vegetation and 11 species were found in both habitats (Table S1). The indirect influence by mango on these plant species was an order of magnitude stronger than the influence in the opposite direction (Effect of mango (mean \pm se) $=0.171 \pm 0.015 ;$ Effect on mango $=0.010 \pm 0.002, \mathrm{t}=11.1$, $\mathrm{p}<0.001$ ), indicated by the larger width of the links at mango than at the plants connected to it in Fig. 1b.

The mean indirect effect on mango of plant species flowering when mango was not in flower was less than that of plants flowering at the same time as mango $(0.011 \pm 0.001$ and $0.0230 \pm 0.006)$. The mean effect of plant species in natural vegetation was greater than that of species in mango fields during mango flowering $(0.051 \pm 0.01$ and $0.02 \pm 0.01$, respectively). When networks were aggregated at landscape scale (i.e. aggregated network across all farms), this trend remained, although it was less marked (Mango fields: $0.03 \pm 0.02$; Natural Vegetation: $0.04 \pm 0.04$ ). The summed (cumulative) effect of species growing in natural vegetation was also greater than the summed effect of plants found in mango fields. The cumulative effect on mango during mango flowering by plant species growing in mango fields was 0.26 and indirect effects by plant species in natural vegetation summed to 0.40 . When mango was not flowering, the summed indirect effect by plants in mango fields was 0.73 and that from natural vegetation of 0.77 .

This could be linked to species richness in the two habitats. There were more species flowering when mango was not in flower, in both mango fields and natural vegetation (Fig. 2). When mango was not flowering, the mean number of flowering species in plots in mango field was $7.9 \pm 1.09$; in natural vegetation, there were $12.5 \pm 1.01$ species flowering. When mango was in flower, there were $3.9 \pm 0.38$ other flowering species in mango fields, compared to $1.3 \pm 0.44$ in natural vegetation.

\subsection{Factors affecting potential indirect effects between mango and other plant species}

When all flower visitors were considered together, whether or not a plant species had an effect on mango was determined by high flower abundance and habitat, with plants found in mango fields having greater probability of interacting indirectly with mango than plants growing in natural vegetation $\left(\chi^{2}=35.6\right.$, df $=5, \mathrm{p}<0.0001$, Table 1), but not by plant flowering time (i.e. during mango flowering or when mango was not flowering). The strength of the interaction was determined by flower abundance, time of flowering and habitat. Plants growing in natural vegetation showed a significantly lower rate of increase in effect strength with increasing flower abundance than plant species flowering in mango fields (Table 1, Fig. 3). In addition, species flowering at the same time as mango had a significantly higher indirect effect on mango. $\chi^{2}=35.2$, df $\left.=8, \mathrm{p}<0.001\right)$.

In cases where mango had no effect on other plant species, they also had no effect on mango i.e. Müller's index was zero. Therefore whether there was an effect or not of mango on other plant species was determined by the same variables as for the effect on mango. The best model for the strength of the effect of mango on other plant species suggested that mango has less of an effect on plants growing in natural vegetation than on plants growing in mango fields. Furthermore, its effect on other species as a function of flower abundance increased at a lower rate when mango was not flowering $\chi^{2}=21.6$, $\mathrm{df}=7$, $\mathrm{p}<0.001$ (Table 1). 


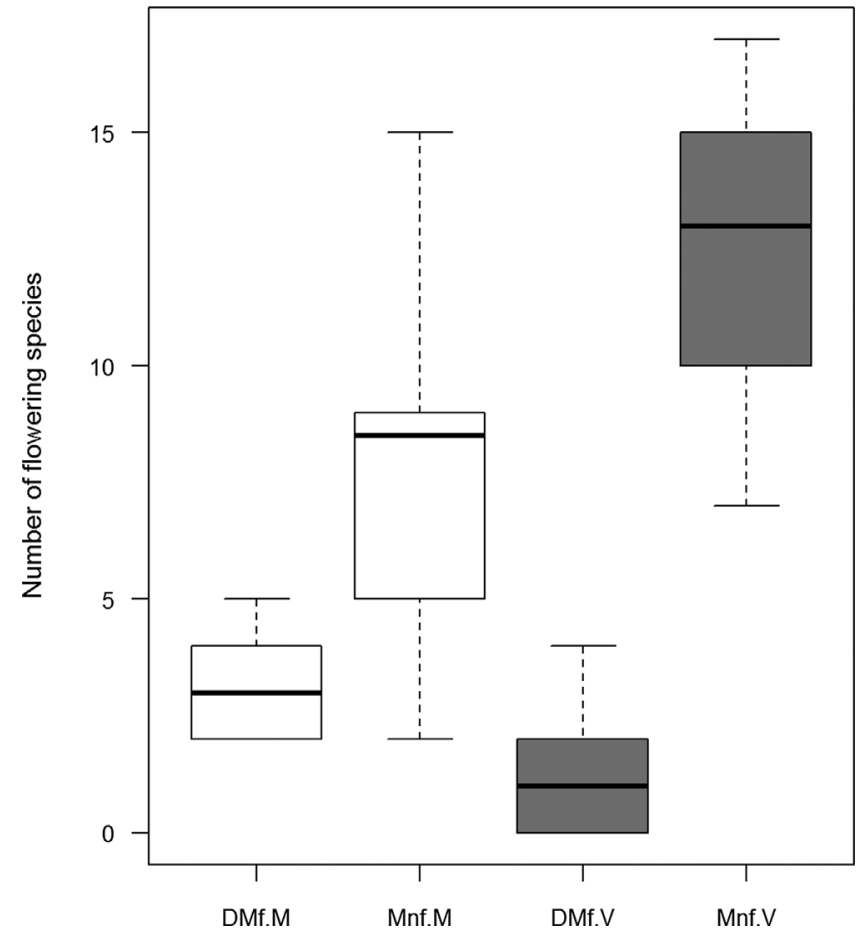

Fig. 2. Number of flowering species in mango fields (white) and neighbouring natural vegetation (grey), during mango flowering and when mango is not flowering. "DMf" indicates the time during mango flowering, "Mnf" indicates when mango was not flowering. "V" indicates species in natural vegetation bordering mango fields and " $\mathrm{M}$ " indicates those found in mango fields. Mango flowers in the dry winter season, thus number of flowering species is lower in both habitats.

\subsection{Indirect effects mediated by different taxonomic groups of flower visitors}

Flower visitor assemblages were dominated by different taxonomic groups in the two habitat types. In mango fields, flies (33\%) and bees
(32\%) were dominant, followed by ants (16\%) and beetles (8\%), whereas in natural vegetation, ants $(63 \%)$ were the most common flower visitors, followed by beetles (9\%), bees $(8 \%)$ and flies $(7 \%)$. Flowering plants visited by mango flower visitors after mango has ceased flowering included Cissus rotundifolia, Acacia (Senegalia) nigrescens, Grewia flava, Zantedeschia aethiopica, Dichrostachys cinerea, Sclerocarya birrea, Commelina africana and Indigofera filipes. Plant species that supported mango flower visitors throughout, i.e., before, during and after mango flowering season, were all non-native species: Lantana camara, Tridax procumbens, Bidens pilosa.

The patterns of indirect interactions varied for different taxonomic groups (Fig. 4). Flies visited mango often, indicated by the large size of the circle around mango (plant species 6 in Fig. 4b) and tended to be observed often on mango, indicated by the amount of grey filling for plant species 6 in Fig. 4b. Ants, although also often observed visiting mango flowers, visited many other species of plant as well, a visitation pattern that seemed fairly random compared to other groups (illustrated by the small size of the greyed in circle around plant species 6 in Fig. 4 d, and the even spread of links to other species).

\section{Discussion}

The findings of this study underscore the importance of evaluating flower visitor networks over time, and for plant species both within and beyond flowering crops, to more accurately interpret the contributions of these plant species to supporting crop flower visitors. In demonstrating that flowering crops can share flower visitors with both native plants and exotic intra-crop weeds, and that these plants can provide a key supportive role to the crop itself, an important link emerges between temporal effects and diversity of natural vegetation.

\subsection{Size of potential effects between mango and plant species in cropland and natural vegetation}

Mango shared all but $15 \%$ of its flower visitors with 38 plant species, and natural vegetation harboured three times the number of shared flower species than did exotic weeds in mango fields. Ultimately,

Table 1

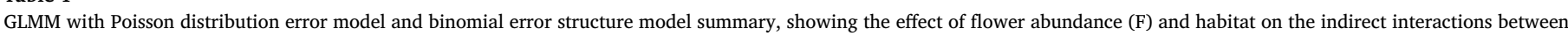

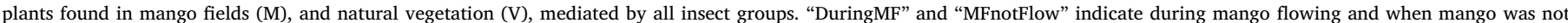

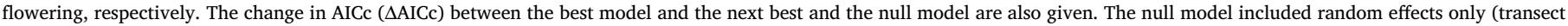

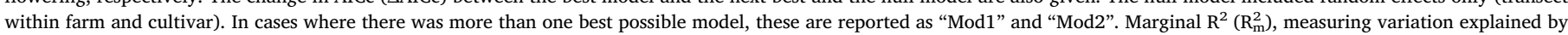
fixed effects only, and conditional $\mathrm{R}^{2}\left(\mathrm{R}_{\mathrm{c}}^{2}\right)$, measuring variation explained by both fixed and random effects, are given.

\begin{tabular}{|c|c|c|c|c|c|c|}
\hline Response & Model & $\begin{array}{l}\text { AICc (Best } \\
\text { model) }\end{array}$ & $\begin{array}{l}\triangle \mathrm{AICc} \\
\text { (second best) }\end{array}$ & $\begin{array}{l}\Delta \text { AICc } \\
\text { (null) }\end{array}$ & $\mathrm{R}_{\mathrm{m}}^{2}$ & $\mathrm{R}_{\mathrm{c}}^{2}$ \\
\hline \multicolumn{7}{|l|}{ Indirect interaction models } \\
\hline \multicolumn{7}{|c|}{ All insects: Effect on mango } \\
\hline & Best model & & & & & \\
\hline \multirow{2}{*}{$\begin{array}{l}\text { The presence of an indirect } \\
\text { interaction }\end{array}$} & $\sim$ Flower abundance ${ }^{* * *}+$ Habitat** & 194.4 & 7.3 & 23 & 0.78 & 0.80 \\
\hline & Best model equation: $\mathrm{Y}=\mathrm{e}_{10}^{-0.59+0.99 \times \log (\mathrm{F})-1.16 \mathrm{~V}}$ & & & & & \\
\hline \multirow{2}{*}{$\begin{array}{l}\text { The strength of the indirect } \\
\text { interaction on mango }\end{array}$} & $\sim$ Flower.abundance ${ }^{* * *}+$ Habitat $* *+$ Flower.abundance: Habitat ${ }^{* *}+$ Season $*$ & -619.0 & 1.52 & 23.15 & 0.18 & 0.21 \\
\hline & $\begin{array}{l}\text { Predicted model parameters using model averaging: } \\
\mathrm{Y}=\mathrm{e}_{10}^{-5.9+1.4 \mathrm{~V}+0.5 \log (\mathrm{F})-0.1 \mathrm{M} \text { FnotFlow }-0.32 \mathrm{~V}: \log (\mathrm{F})-0.8 \mathrm{~V}: \text { MFnotFlow }}\end{array}$ & & & & & \\
\hline \multicolumn{7}{|c|}{ All insects: Effect of mango } \\
\hline & Best model & & & & & \\
\hline \multirow{2}{*}{$\begin{array}{l}\text { The presence of an indirect } \\
\text { interaction }\end{array}$} & $\sim$ Flower abundance ${ }^{* * *}+$ Habitat ${ }^{* *}$ & 194.4 & 7.3 & 23 & 0.78 & 0.80 \\
\hline & Best model equation: $\mathrm{Y}=\mathrm{e}_{10}^{-0.59+0.99 \times \log (\mathrm{F})-1.16 \mathrm{~V}}$ & & & & & \\
\hline \multirow{3}{*}{$\begin{array}{l}\text { The strength of the indirect } \\
\text { interaction by mango }\end{array}$} & Mod1: $\sim$ Habitat ${ }^{* * *}+$ Flower.abundance: Season ${ }^{* *}$ & -91.6 & 0.7 & 12.6 & 0.17 & 0.17 \\
\hline & Mod2: $\sim$ Season*** + Flower.abundance: Habitat* & -90.9 & & & & \\
\hline & $\begin{array}{l}\text { Predicted model parameters using model averaging: } \mathrm{Y}=\mathrm{e}^{-} \\
0.9-0.1 \mathrm{~V}+0.02 \log _{1010}(\mathrm{~F})+0.12 \mathrm{MFN} \text { (tFlow }-0.15 \text { MFnotFlow: } \log (\mathrm{F})-0.16 \mathrm{~V}: \log 10(\mathrm{~F})\end{array}$ & & & & & \\
\hline
\end{tabular}

P values: $<0.1 ; *,<0.05 ; * *,<0.01 ; * * *,<0.001$ 

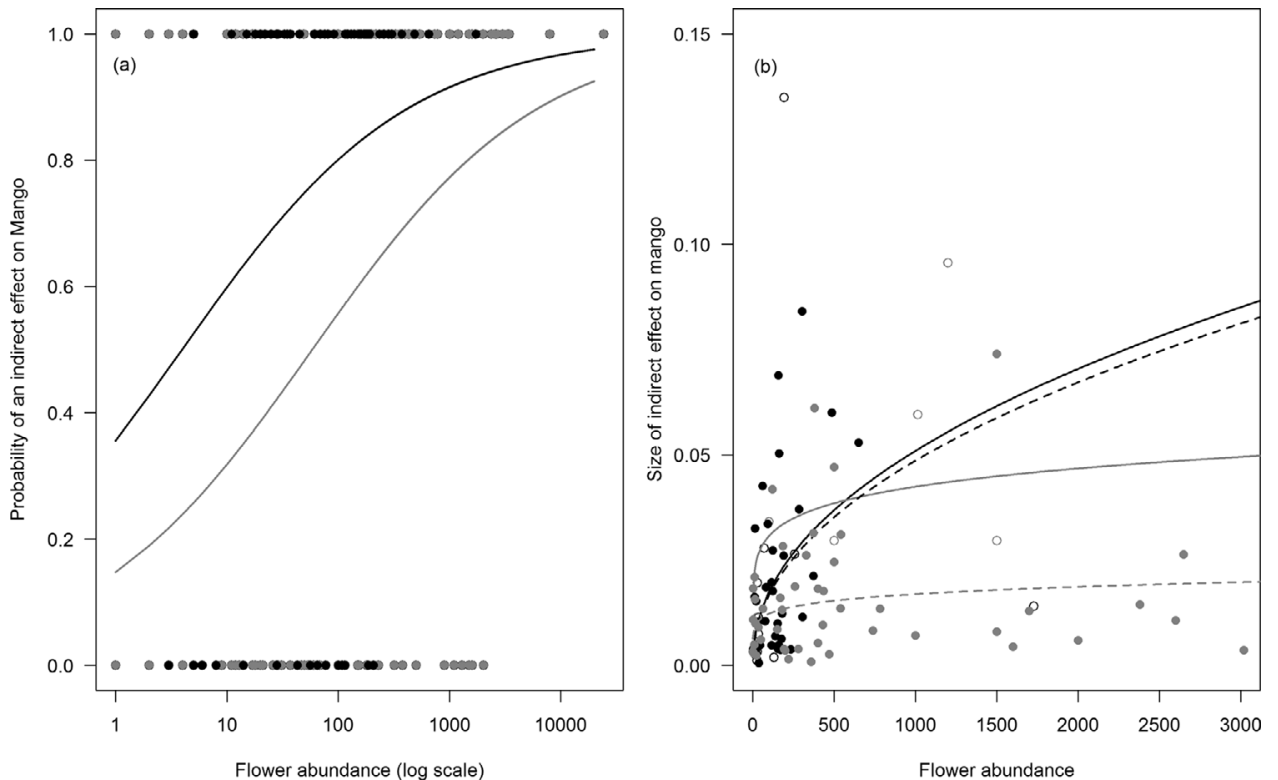

Fig. 3. (a) The probability of an indirect effect of a plant species on mango as a function of flower abundance and (b) The strength of an indirect effect by a plant species on mango as a function of flower abundance. The relationship for plants found in mango fields is indicted in black, for plants in natural vegetation, in grey. Where there was a seasonal effect, solid lines indicate the strength during mango flowering, dashed lines the strength of the effect when mango was not flowering.
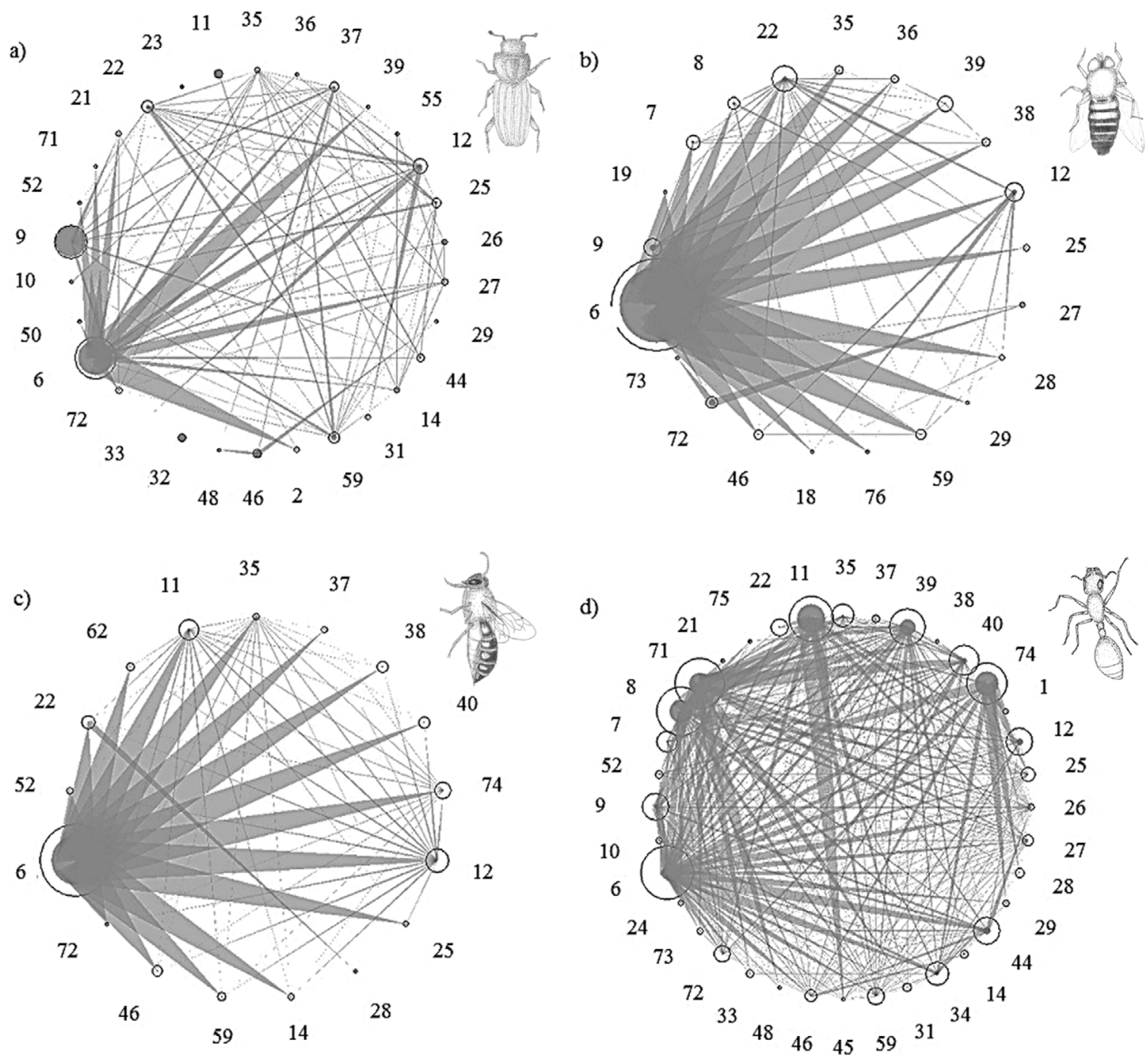

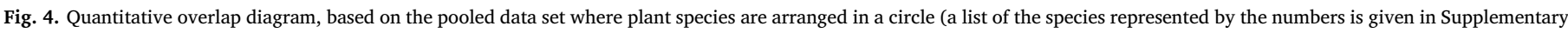

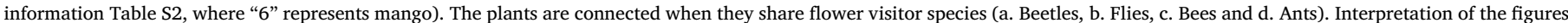
is as for Fig. $1 \mathrm{~b}$. 
$53 \%$ of plant species that shared flower visitors occurred in natural vegetation, $29 \%$ were in both habitats, whereas $18 \%$ were exotic weeds found only in mango fields.

During mango flowering, the cumulative indirect effect of other plant species in natural vegetation on mango was marked, being 1.5 times that of exotic weed species found in mango fields ( $0.26 \mathrm{vs}$. 0.40$)$. As noted, these plants may have been either facilitating, or competing with mango. When mango was not flowering, the summed effect of other species was high for plant species from both habitats (Summed effects of species in mango $=0.73$; natural vegetation $=0.77$ ). These results suggest a general trend for facilitation by both native plants found in natural vegetation and by crop weeds. Given that the plant species in natural vegetation displayed different phenologies (van der Walt, 2009), this diversity of species was available to support flower visitors over long time periods.

The effect of mango on other species was much greater than that in the opposite direction, perhaps because the probability and strength of indirect interactions was a function of flower abundance, and mango flowers super-abundantly. That said, the strength of the interaction is unlikely to have been solely determined by flower abundance, given that factors including nectar and pollen reward (Hoover et al., 2012; Schiestl and Johnson, 2013), flower colour (Campbell et al., 2010), and odours (Cunningham et al., 2006; Junker et al., 2010) have also been shown to predict the number of interactions.

In this study, the importance of temporal effects became apparent because we sampled over many months, which enabled detection of the subtle supportive indirect effects of other plant species for mango flower visitors over time. Although species that flowered when mango itself flowered are likely to be facilitating the crop by harbouring and supporting flower visitors, it is possible that some species may be competing with the crop for flower visitors. This possibility (of competition) is excluded for plant species that flowered when mango was not in flower, because these species can be considered to facilitate the crop by supporting flower visitors when mango was not flowering.

\subsection{Factors affecting potential indirect effects between mango and plant species}

The likelihood and strength of indirect effects on the crop by other plant species increased with flower abundance, but this rate of increase in strength of effect was lower for plant species growing in natural vegetation than for plant species growing in mango fields. Flower abundance is often an important predictor of indirect interactions, as a greater number of flowers equates to a greater chance of being encountered, patches containing many flowers can be more easily detected (Schiestl and Johnson, 2013), and pollinators tend to visit more inflorescences in larger patches of flowers (Goulson, 2000). That the strength of indirect effects increased with flower abundance at a greater rate for weeds and exotic plant species flowering in mango fields than for species growing in natural vegetation highlights the value of weeds in supporting flower visitors, an observation that has been noted elsewhere (Carvalheiro et al., 2011; Nel et al., 2017). This may be because (a) flowering plants in natural vegetation are more dispersed; (b) weeds flowered consistently and abundantly; and (c) weeds are in close proximity to the mango flowers, so energy expenditure to reach these flowers is minimised. In addition, edaphic factors can impact plant tissue chemistry and morphology, and soils can both directly and indirectly influence plant-insect interactions through changing floral chemistry and display (Meindl et al., 2013). Weeds and exotic plants in mango fields may offer more resources per flower, because they grow in a watered and fertilized environment, compared to species growing in the natural vegetation. Additional water and fertilizer added to soils within mango orchards allows plant species in mango orchards to have not only abundant flowers, but also an extended flowering period.

Natural vegetation provided a diversity of plant species catering for a broad spectrum of flowering times spanning much of the year. Thus the cumulative effect of species growing in natural vegetation on mango was greater than that for plants growing in mango fields. Weeds also emerged as important for supporting mango flower visitors. The implications of this are important within the current global context of rapidly receding natural vegetation and removal of intra-crop weeds from agricultural systems in efforts to maximise landuse for crops and optimise yields (Ben-Ari and Makowski, 2016; Brown et al., 2016; Fennimore et al., 2014).

\subsection{Indirect effects mediated by different taxonomic groups of flower visitors}

The presence of this mass-flowering crop and its associated weeds strongly influenced the composition of insect communities. As we hypothesised, different insect groups displayed different patterns of floral visitation, and abundances of these groups differed markedly between crop and natural vegetation (Fig. 4).

Flies and bees were dominant in mango, whereas ants and beetles tended to be the dominant flower visitors in natural vegetation. Floral characteristics of the most dominant species likely explain the differences in insect group representation between mango plants and those in natural vegetation. Different groups of flower visitors are attracted by various floral characteristics: plants that offer more nectar receive proportionally more visits from bees (Carvalheiro et al., 2014), and preferences for different flower colours also influence the dominant groups seen (Campbell et al., 2010). Foraging behaviour, also known to be important (Brunet et al., 2015; Del-Claro et al., 2016), may explain why ants, the only non-flying group amongst those considered, visited a greater proportion of flowering plants (but in a less consistent or predictable, directed, manner Fig. 4). These differences provide insight into the changes that flower-bearing crops and their associated weeds can bring about for the composition of insect assemblages at the landscape scale.

\subsection{Concluding comments}

Without consideration of the temporal impacts to flower visitors that occur in the non-flowering season of crops, ecologically meaningful indirect effects can be overlooked. Here we show that species that flower at other times of the year relative to the crop can maintain strong interactions via shared flower visitors, and that these interactions are likely to facilitate crop flower visitors over the course of the year. Such interactions occur not only within crop flowering season and from intra-crop weeds, but because of flowering phenologies of surrounding plants in natural vegetation. The favouring of distinct taxonomic groups of invertebrate flower visitors by a mass-flowering crop (in this example, flies and bees over beetles and ants) is noteworthy within the context of the rapid expansion in high-intensity, high-yield monoculture plantings (Fennimore et al., 2014). The current trend toward monocultures and maximising crop area is likely to have long-term deleterious impacts on flower-visitation to crops that depend on flower visitors from a diversity of contiguous vegetation. It is also likely to impact invertebrate communities as groups associated with the flowering crop could increase at the expense of others (Geslin et al., 2017). Ultimately this may alter not only assemblages, but trophic webs. Although not tested for in this study, such effects can be anticipated to impact not only invertebrate communities, but also crop yields.

The findings of these types of studies are likely to vary with crop type and flowering time. Mango flowers in the dry season, when little else is flowering, so the high abundance of mango and weed flowers likely attracted and supported numerous flower visitors from the far less flower-rich surrounds. Crops that flower in the wet season may have very different influences on and by flower-visitor communities and native plants in the surrounding vegetation. Future reviews and meta-analyses on the effects of crops on natural vegetation and viceversa may need to consider the influence of crop flowering season. 
Network analysis in this study emphasised that flower abundance best predicted indirect effects of wild plants on mango flower visitation, but also revealed the value and cumulative effect of natural vegetation and crop field weeds in supporting crop flower visitors, particularly when the crop is not in flower. Such effects have to date rarely been considered in crop pollination studies, and warrant further investigation, as far-ranging consequences can be anticipated for conservation of natural systems, integrity of agricultural systems, and ultimately human wellbeing, at a range of scales (Bohan, 2016).

\section{Acknowledgements}

We thank C. Schoeman and C. Munyai for insect identification; the management in Bavaria, Venden and Mohlatsi farms; L. Nel and the University of Venda students for field assistance; D. Khosa for lab assistance. Financial support was received from the National Research Foundation (NRF Grant number 90139), European Union Marie Curie IRSES project NETWORK (grant agreement: PIRSES-GA-2012-318929), Department of Science and Technology of South Africa (grant number DST/CON0054/2013). Two anonymous reviewers and the handling editor gave constructive criticisms, which improved the manuscript.

\section{Appendix A. Supplementary data}

Supplementary data associated with this article can be found, in the online version, at https://doi.org/10.1016/j.agee.2017.11.002.

\section{References}

Archer, C.R., Pirk, C.W.W., Carvalheiro, L.G., Nicolson, S.W., 2014. Economic and ecological implications of geographic bias in pollinator ecology in the light of pollinator declines. Oikos 123, 401-407. http://dx.doi.org/10.1111/j.1600-0706.2013. 00949.x.

Baldock, K.C.R., Memmott, J., Carlos Ruiz-Guajardo, J., Roze, D., Stone, G.N., 2011. Daily temporal structure in African savanna flower visitation networks and consequences for network sampling. Ecology 92, 687-698. http://dx.doi.org/10.1890/10-1110.1.

Barton, K., 2016. MuMIn: Multi-model inference, R package V 1.15.6, https://CRAN.R project.org/package $=$ MuMIn .

Ben-Ari, T., Makowski, D., 2016. Analysis of the trade-off between high crop yield and low yield instability at the global scale. Environ. Res. Lett. 11, 104005. http://dx.doi. org/10.1088/1748-9326/11/10/104005.

Bjerknes, A.L., Totland, Ø., Hegland, S.J., Nielsen, A., 2007. Do alien plant invasions really affect pollination success in native plant species? Biol. Conserv. 138, 1-12.

Bohan, D.A., 2016. Networking our way to better ecosystem service provision. Trends Ecol. Evol. 31, 105-115. http://dx.doi.org/10.1016/j.tree.2015.12.003.

Brown, M.J.F., Dicks, L.V., Paxton, R.J., Baldock, K.C.R., Barron, A.B., Chauzat, M.-P., Freitas, B.M., Goulson, D., Jepsen, S., Kremen, C., Li, J., Neumann, P., Pattemore, D.E., Potts, S.G., Schweiger, O., Seymour, C.L., Stout, J.C., 2016. A horizon scan of future threats and opportunities for pollinators and pollination. Peer J. 4, e2249. http://dx.doi.org/10.7717/peerj.2249.

Brunet, J., Thairu, M.W., Henss, J.M., Link, R.I., Kluever, J.A., 2015. The effects of flower, floral display, and reward sizes on bumblebee foraging behavior when pollen is the reward and plants are dichogamous. Int. J. Plant Sci. 176, 811-819. http://dx.doi. org/10.1086/683339.

Campbell, D.R., Bischoff, M., Lord, J.M., Robertson, A.W., 2010. Flower color influences insect visitation in alpine New Zealand. Ecology 91, 2638-2649. http://dx.doi.org/ 10.1890/09-0941.1.

Carvalheiro, L.G., Barbosa, E.R.M., Memmott, J., 2008. Pollinator networks, alien species and the conservation of rare plants: Trinia glauca as a case study. J. Appl. Ecol. 45, 1419-1427.

Carvalheiro, L.G., Seymour, C.L., Veldtman, R., Nicolson, S.W., 2010. Pollination services decline with distance from natural habitat even in biodiversity-rich areas. J. Appl. Ecol. 47, 810-820. http://dx.doi.org/10.1111/j.1365-2664.2010.01829.x.

Carvalheiro, L.G., Veldtman, R., Shenkute, A.G., Tesfay, G.B., Pirk, C.W.W., Donaldson, J.S., Nicolson, S.W., 2011. Natural and within-farmland biodiversity enhances crop productivity. Ecol. Lett. 14, 251-259. http://dx.doi.org/10.1111/j.1461-0248.2010. 01579.x.

Carvalheiro, L.G., Seymour, C.L., Nicolson, S.W., Veldtman, R., 2012. Creating patches of native flowers facilitates crop pollination in large agricultural fields: mango as a case study. J. Appl. Ecol. 49, 1373-1383.

Carvalheiro, L.G., Biesmeijer, J.C., Benadi, G., Fründ, J., Stang, M., Bartomeus, I., KaiserBunbury, C.N., Baude, M., Gomes, S.I.F., Merckx, V., Baldock, K.C.R., Bennett, A.T.D., Boada, R., Bommarco, R., Cartar, R., Chacoff, N., Dänhardt, J., Dicks, L.V., Dormann, C.F., Ekroos, J., Henson, K.S.E., Holzschuh, A., Junker, R.R., Lopezaraiza-Mikel, M., Memmott, J., Montero-Castaño, A., Nelson, I.L., Petanidou, T., Power, E.F., Rundlöf, M., Smith, H.G., Stout, J.C., Temitope, K., Tscharntke, T., Tscheulin, T., Vilà, M., Kunin, W.E., 2014. The potential for indirect effects between co-flowering plants via shared pollinators depends on resource abundance, accessibility and relatedness. Ecol. Lett. 17, 1389-1399. http://dx.doi.org/10.1111/ele.12342.

Cunningham, J.P., Moore, C.J., Zalucki, M.P., Cribb, B.W., 2006. Insect odour perception: recognition of odour components by flower foraging moths. Proc. R. Soc. B Biol. Sci. 273, 2035-2040. http://dx.doi.org/10.1098/rspb.2006.3559.

Del-Claro, K., Rico-Gray, V., Torezan-Silingardi, H.M., Alves-Silva, E., Fagundes, R., Lange, D., Dáttilo, W., Vilela, A.A., Aguirre, A., Rodriguez-Morales, D., 2016. Loss and gains in ant-plant interactions mediated by extrafloral nectar: fidelity, cheats, and lies. Insectes Soc. 63, 207-221. http://dx.doi.org/10.1007/s00040-016-0466-2.

Dormann, C.F., Gruber, B., Fruend, J., 2008. Introducing the bipartite package: analysing ecological networks. R. News 8, 8-11.

Ehlers Smith, Y.C., Ehlers Smith, D.A., Seymour, C.L., Thébault, E., van Veen, F.J.F. 2015. Response of avian diversity to habitat modification can be predicted from lifehistory traits and ecological attributes. Landsc. Ecol. 30, 1225-1239. http://dx.doi. org/10.1007/s10980-015-0172-x.

Fennimore, S.A., Hanson, B.D., Sosnoskie, L.M., Samtani, J.B., Datta, A., Knezevic, S.Z., Siemens, M.C., 2014. Field applications of automated weed control: western hemisphere. In: Young, S.L., Pierce, F.J. (Eds.), Automation: The Future of Weed Control in Cropping Systems. Springer Science + Business Media, Dordrecht, pp. 151-169. http://dx. doi.org/10.1007/978-94-007-7512-1.

Food and Agricultural Organisation of the United Nations, 2009. Food and Agricultural Organisation of the United Nations. Africa's Sleeping Giant (WWW Document).

Food and Agriculture Organisation, 2003. Medium-term Prospects for Agricultural Commodities: Projections to the Year 2010. (WWW Document).

Geslin, B., Oddie, M., Folschweiller, M., Legras, G., Seymour, C.L., van Veen, F.J.F., Thébault, E., 2016. Spatiotemporal changes in flying insect abundance and their functional diversity as a function of distance to natural habitats in a mass flowering crop. Agric. Ecosyst. Environ. 229, 21-29. http://dx.doi.org/10.1016/j.agee.2016. 05.010.

Geslin, B., Gauzens, B., Baude, M., Dajoz, I., Fontaine, C., Henry, M., Ropars, L., Rollin, O. Thébault, E., Vereecken, N.J., 2017. Massively introduced managed species and their consequences for plant?pollinator interactions. Adv. Ecol. Res. 57, 147-199.

Gibson, R.H., Nelson, I.L., Hopkins, G.W., Hamlett, B.J., Memmott, J., 2006. Pollinator webs, plant communities and the conservation of rare plants: arable weeds as a case study. J. Appl. Ecol. 43, 246-257.

Goulson, D., 2000. Why do pollinators visit proportionally fewer flowers in large patches? Oikos 91, 485-492. http://dx.doi.org/10.1034/j.1600-0706.2000.910309.x.

Hagen, M., Kraemer, M., 2010. Agricultural surroundings support flower?visitor networks in an Afrotropical rain forest. Biol. Conserv. 143, 1654-1663. http://dx.doi.org/10. 1016/j.biocon.2010.03.036.

Henri, D.C., Jones, O., Tsiattalos, A., Thébault, E., Seymour, C.L., van Veen, F.J.F., 2015 Natural vegetation benefits synergistic control of the three main insect and pathogen pests of a fruit crop in southern Africa. J. Appl. Ecol. 52, 1092-1101. http://dx.doi. org $/ 10.1111 / 1365-2664.12465$.

Hoover, S.E.R., Ladley, J.J., Shchepetkina, A.A., Tisch, M., Gieseg, S.P., Tylianakis, J.M., 2012. Warming, CO2, and nitrogen deposition interactively affect a plant-pollinator mutualism. Ecol. Lett. 15, 227-234.

Johnson, P.C.D., 2014. Extension of Nakagawa \& Schielzeth's $\mathrm{R}^{2}$ GLMM to random slopes models. Methods Ecol. Evol. 5, 944-946. http://dx.doi.org/10.1111/2041-210X. 12225.

Junker, R.R., Höcherl, N., Blüthgen, N., 2010. Responses to olfactory signals reflect network structure of flower-visitor interactions. J. Anim. Ecol. 79, 818-823. http:// dx.doi.org/10.1111/j.1365-2656.2010.01698.x.

Klein, A.-M., Vaissière, B.E., Cane, J.H., Steffan-Dewenter, I., Cunningham, S.A., Kremen, C., Tscharntke, T., 2007. Importance of pollinators in changing landscapes for world crops. Proc. R. Soc. B 274, 303-313. http://dx.doi.org/10.1098/rspb.2006.3721.

Müller, C.B., Adriaanse, I.C.T., Belshaw, R., Godfray, H.C.J., 1999. The structure of an aphid-parasitoid community. J. Anim. Ecol. 68, 346-370.

McIntyre, B.D., Herren, H.R., Wakhungu, J., Robert Watson, T., 2009. Agriculture at Crossroads. International Assessment of Agricultural Knowledge, Science and Technology for Development (IAASTD). Synthesis Report, Washington DC.

Meindl, G., Bain, D., Ashman, T.-L., 2013. Edaphic factors and plant-insect interactions: direct and indirect effects of serpentine soil on florivores and pollinators. Oecologia 1355-1366.

Memmott, J., 2009. Food webs: a ladder for picking strawberries or a practical tool for practical problems? Philos. Trans. R. Soc. London B: Biol. Sci 364, 1693-1699.

Morgan, W.H., Thébault, E., Seymour, C.L., van Veen, F.J.F., 2017. Density dependence and environmental factors affect population stability of an agricultural pest and its specialist parasitoid. BioControl 62, 175-184. http://dx.doi.org/10.1007/s10526016-9777-5.

Moxley, C., Lammers, W., van Veen, F.J.F., Thébault, E., Esler, K.J., Seymour, C.L., 2017 A major subtropical fruit pest accumulates in crop fields and spills over to a wild host. Agric. Ecosyst. Environ. 242, 102-109.

Nakagawa, S., Schielzeth, H., 2013. A general and simple method for obtaining $\mathrm{R}^{2}$ from generalized linear mixed-effects models. Methods Ecol. Evol. 4, 133-142. http://dx. doi.org/10.1111/j.2041-210x.2012.00261.x.

Nakagawa, S., Johnson, P.C.D., Schielzeth, H., 2017. The coefficient of determination $\mathrm{R}^{2}$ and intra-class correlation coefficient from generalized linear mixed-effects models revisited and expanded. J. R. Soc. Interface 14, 20170213. http://dx.doi.org/10. 1098/rsif.2017.0213.

Nel, L., Pryke, J.S., Carvalheiro, L.G., Thébault, E., van Veen, F.J.F., Seymour, C.L., 2017. Exotic plants growing in crop field margins provide little support to mango crop flower visitors. Agric. Ecosyst. Environ. 250, 72-80.

Pocock, M.J.O., Evans, D.M., Fontaine, C., Harvey, M., Julliard, R., McLaughlin, Ó., Silvertown, J., Tamaddoni-Nezhad, A., White, P.C.L., Bohan, D.A., 2016. The visualisation of ecological networks, and their use as a tool for engagement, advocacy and 
management. Adv. Ecol. Res. http://dx.doi.org/10.1016/bs.aecr.2015.10.006.

Ricketts, T.H., Regetz, J., Steffan-Dewenter, I., Cunningham, S.A., Kremen, C., Bogdanski, A., Gemmill-Herren, B., Greenleaf, S.S., Klein, A.M., Mayfield, M.M., Morandin, L.A., 2008. Landscape effects on crop pollination services: are there general patterns? Ecol. Lett. 11, 499-515.

Riedinger, V., Renner, M., Rundlöf, M., Steffan-Dewenter, I., Holzschuh, A., 2014. Early mass-flowering crops mitigate pollinator dilution in late-flowering crops. Landsc. Ecol. 29, 425-435. http://dx.doi.org/10.1007/s10980-013-9973-y.

Sauve, A.M.C., Thébault, E., Pocock, M.J.O., Fontaine, C., 2016. How plants connect pollination and herbivory networks and their contribution to community stability. Ecology 97, 908-917. http://dx.doi.org/10.1890/15-0132.1.

Schiestl, F.P., Johnson, S.D., 2013. Pollinator-mediated evolution of floral signals. Trends Ecol. Evol. 28, 307-315. http://dx.doi.org/10.1016/j.tree.2013.01.019.

Sotomayor, D.A., Lortie, C.J., 2015. Indirect interactions in terrestrial plant communities: emerging patterns and research gaps. Ecosphere 6 (rt103). http://dx.doi.org/10.
1890/ES14-00117.1.

Stang, M., Klinkhamer, P.G., Van Der Meijden, E., 2006. Size constraints and flower abundance determine the number of interactions in a plant-flower visitor web. Oikos $112,111-121$

Stone, G.N., Willmer, P., Alexandra Rowe, J., 1998. Partitioning of pollinators during flowering in an African Acacia community. Ecology 79, 2808-2827. http://dx.doi. org/10.2307/176518.

Westphal, C., Steffan-Dewenter, I., Tscharntke, T., 2003. Mass flowering crops enhance pollinator densities at a landscape scale. Ecol. Lett. 6, 961-965. http://dx.doi.org/10. 1046/j.1461-0248.2003.00523.x.

Williams, N.M., Kremen, C., 2007. Resource distributions among habitats determine solitary bee offspring production in a mosaic landscape. Ecol. Appl. 17, 910-921.

van der Walt, R., 2009. Wild Flowers of the Limpopo Valley. Retha van der Walt, Ludwigslust Game Farms, Musina, South Africa. 